\title{
A case of congenital obstruction of magendie's foramen: embryologic analysis and treatment
}

\author{
HA N'da*, S Fondjo, LK Drogba, LM Konan and V Ba Zeze
}

\begin{abstract}
Background: Fourth ventricle isolated Magendie's foramen primitive obstruction is rare. The etiology and the pathophysiology of the constitution of this obstruction in congenital cases remain elusive. We report a case of congenital obstruction of Magendie's foramen in an adult patient and discuss the embryogenic mechanism and our management of this rare pathology.
\end{abstract}

Case presentation: A 20 years old female patient without any medical history was referred for headaches and vomiting. Emergency $C T$ scan revealed major hydrocephalus subsequently she underwent a ventriculoperitoneal shunt as initial treatment.

The diagnosis of fourth ventricle obstruction was made 5 months later when the patient came back complaining of headaches, cerebellar signs and cystic dilatation of the fourth ventricle on CT scan and MRI. Fourth ventricle Magendie's foraminoplasty via classic posterior fossa surgery brings complete cure.

Conclusion: Magendie's foramen obstruction is rare. The embryological development of the posterior fossa and its content could explain the primitive obstruction which can be managed by classic surgery in case of unavaibility of endoscopy.

Keywords: Fourth ventricle outlets, Hydrocephalus, Magendie foramen, Obstruction

\section{Background}

Isolated obstruction of fourth ventricle Magendie's foramen is rare. The development of obstructive hydrocephalus with cerebellum and brain stem compression is its main danger.

Obstruction of Magendie's and Luschka's foramen are included in the pathological group of fourth ventricle outlet obstruction (FVOO) [1]. In FVOO, the obstructive hydrocephalus is caused by a blockage of the CSF at the fourth ventricle by a membranous structure without any obstructive masses [1]. Although Obstruction of Magendie's foramen in infants is usually congenital, this disease is acquired in adults [2].

We report a single case of congenital Magendie's foramen obstruction revealed at adult age and discuss the

\footnotetext{
* Correspondence: drndah@yahoo.fr

Service de neurochirurgie, CHU de Yopougon Abidjan Côte d'Ivoire, 21 BP 632 Abidjan 21, Côte d'Ivoire
}

\section{Biomed Central}

(c) The Author(s). 2017 Open Access This article is distributed under the terms of the Creative Commons Attribution 4.0 International License (http://creativecommons.org/licenses/by/4.0/), which permits unrestricted use, distribution, and reproduction in any medium, provided you give appropriate credit to the original author(s) and the source, provide a link to the Creative Commons license, and indicate if changes were made. The Creative Commons Public Domain Dedication waiver (http://creativecommons.org/publicdomain/zero/1.0/) applies to the data made available in this article, unless otherwise stated.

\section{Case presentation}

A 20 years old female patient with no medical history was referred to our department for 1 month progressive onset of intense headache. On clinical examination, the patient was complaining of worsening headache associated with vomiting. However, no neurologic deficit was noticed. The CT scan revealed an important dilatation of lateral, third and fourth ventricle (Fig. 1). A ventriculoperitoneal shunt was inserted as an urgent treatment of the intracranial high pressure. The outcome was favorable and the patient was discharged 05 days later.

About five months later, the patient complained back of occipital headaches, dizziness and easy vomiting leading to a new hospitalization. The physical examination revealed cerebellar signs including, dysmetria, widebased and unsteady gait. The CT scan showed a cystic dilatation of fourth ventricle (Fig. 2a). The MRI shows 


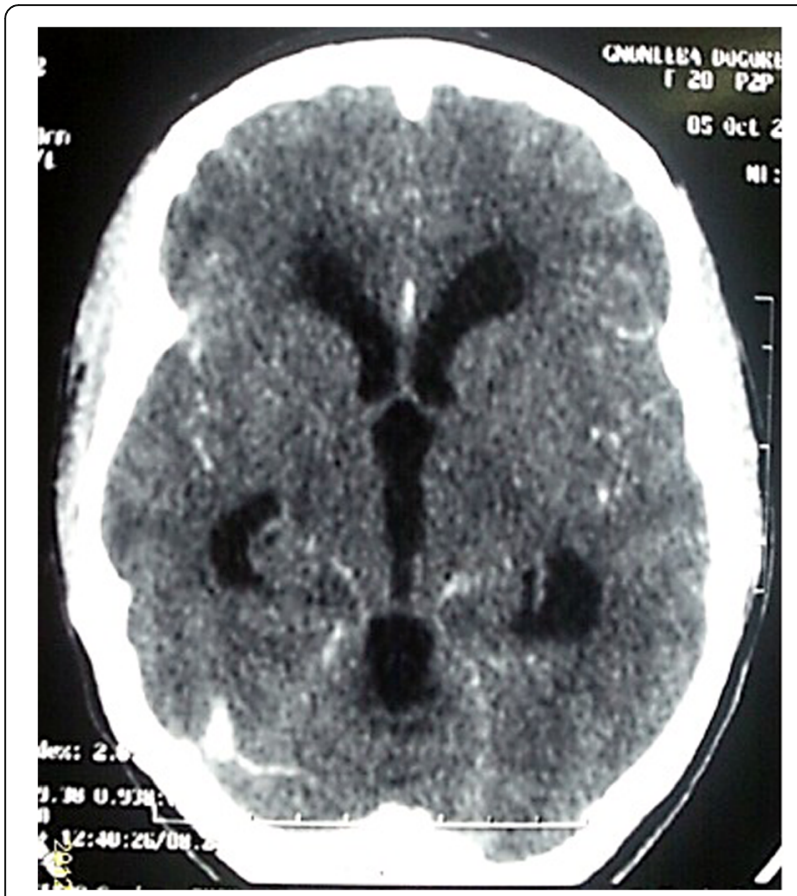

Fig. 1 CT scan showing hydrocephalus with lateral, third and fourth ventricle dilatation

no intraventricular tumoral process on (Fig. 2b). Therefore, this case of isolated fourth ventricle cystic dilatation let us suspect a FVOO. Hence, we performed a surgical procedure with 2 objectives: confirm this diagnosis and treat this congenital malformation.

After posterior fossa midline approach targeting the fourth ventricle, we found out a thin membranous formation obstructing the Magendie's foramen, nonetheless the Luschka's foramen was free. The removal of this membranous was achieved allowing a wide foraminotomy
(Fig. 3). The cerebellar syndrome disappeared a week after surgery. The follow-up two years after surgery were normal.

\section{Discussion and Conclusions}

Isolated Magendie's foramen obstruction is rare. The obstruction can be acquired or congenital. Primitive congenital obstructions are mainly seen in children $[1,3]$ and are more often associated with other malformations such as Dandy-Walker, Arnold Chiari malformation, Bourneville disease, atlanto occipital fusion [4]. The mechanism of obstruction is still unclear [1]. The congenital obstruction of Magendie's foramen could be well explained by the embryological formation of the posterior fossa. The embryogenesis of posterior fossa and its contents take place during the ventral induction process [5]. The hindbrain development occurs during the process of ventral induction in the 5th to 10th week of gestation [5].

The hindbrain structures derive from differentiation of rhombencephalon to an upper vesicle, the metencephalon and to a lower vesicle: the myelencephalon. Subsequently, the myelencephalon gives the pons and the medulla oblongata and this division occurs at the same time that the pontine flexure develops [6]. The rhombic flexure causes the dorsal aspect of the neural tube to open exposing the floor of the 4th ventricle. A Continuous indentation by the pontine flexure results in a widening and thinning roof plate which correspond to the roof of 4th ventricle.

At the 10th week of gestation, the embryonic choroid plexus indents the thinned roof plate to form the "plica choroidalis". This structure separate the roof plate into a superior part, the anterior membrana area and into an inferior part, the posterior membrana area. The CSF fills

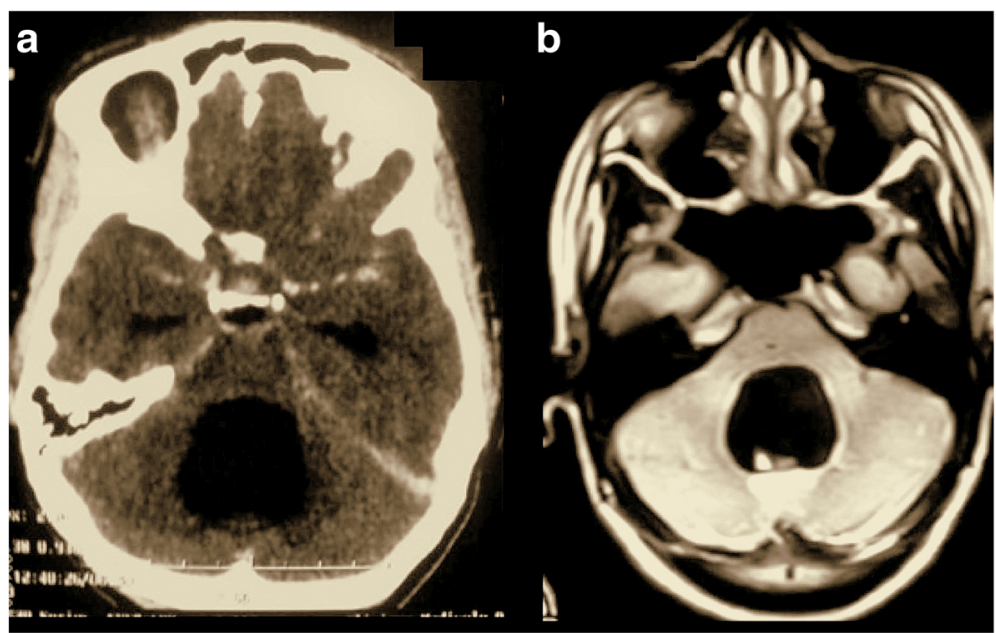

Fig. 2 Dilatation of the fourth ventricle after ventriculoperitoneal shunt insertion. a Cystic dilatation of the fourth ventricle on the CT scan. $\mathbf{b}$ MRI showing the cystic dilatation of the fourth ventricle 


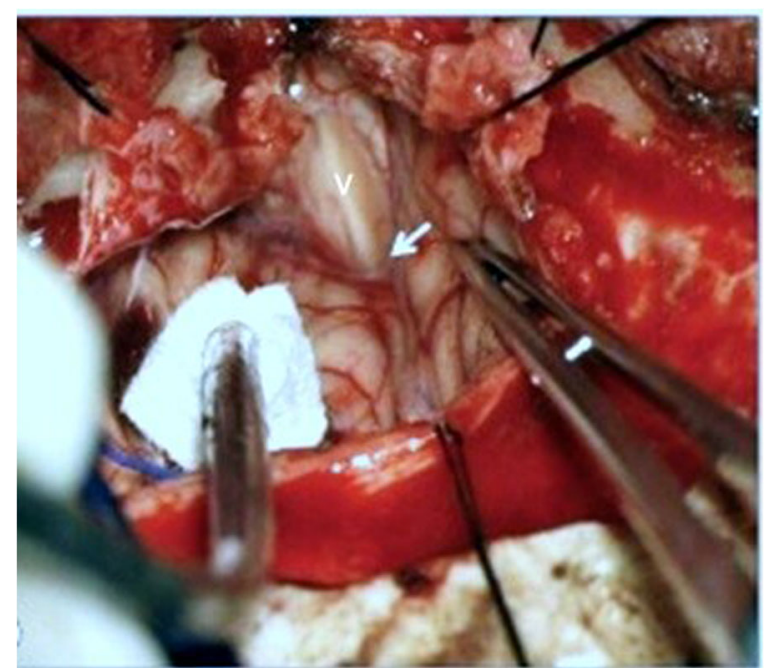

Fig. 3 Magendie's foraminoplasty. V: fourth ventricle, the white arrow shows the flow of CSF through the foramen of Magendie

the inferior part and expands caudally to give the "Blake pouch" on which a secondary permeabilization permit the CSF to be accumulated in the inferior part of the cerebellum to form the cistern magna [7]. The regression of the Blake pouch will result of formation of the Magendie's foramen at the midline and then the lateral angle of the rhomboid fossa give rise to the Luschka's foramen [6]. The non-regression of the Blake pouch results to an isolated congenital atresia of the Magendie's foramen. Many authors claim that congenital obstruction is exhibited early at the childhood and the acquired obstruction during the adulthood [2]. From our point of view this assertion should be clarified. The congenital obstruction is caused by a semipermeable membrane which gives passage of some CSF from the ventricle into the subaranoid space [8]. In a case of atresia, this is rarely absolute. Thus, some CSF may escape through a greatly narrowed foramen [8]. For these reasons an obstruction of Magendie's foramen can remain for a long time compensated so that the onset symptoms should be delayed and revealed at the adult stage. Longatti $P$ et al. [9] have reported ten cases of primary obstruction of the fourth ventricle outlets. These authors revealed endoscopically various type of primitive stenosis such as: restriction of the Magendie's contour with thick and opaque membrane, transparent spider web-like membrane and dense membrane with fissure acting as a valve [9].

The acquired obstruction is usually due to inflammation of the meninges at the base of brain [8]. In case of meningitis, the foramen may be blocked in acute stage by an exudate or in middle stage by fibrous granulation so that symptoms can occur early [9].

In our case, the cyst wall was very thin and transparent. They were no macroscopic element suggesting anterior meningitis and no medical history of factors which can lead to hydrocephalus. These elements are hallmarks of primitive origin of this obstruction.

Atresia of Magendie's and Luschka's foramen can be classically treated by 4th ventricle shunting [9]. In absence of acqueductal stenosis with dilated foramen of Monro allowing the passage of the endoscope, an endoscopic third ventriculostomy to get the 4th ventricle can be made [1]. Many authors preconize a direct foraminoplasty via an endoscopic 4th ventriculostomy [9].

In a context where endoscopy is not available, our preference remain a wide foraminoplasty via a classic posterior fossa route. This foraminoplasty is completed by a dural enlargement surgery allowing a good CSF circulation between 4 th ventricle and the cisterna magna and avoid any new stenosis [10].

In conclusion, Magendie's foramen primitive atresia or obstruction is a rare pathological condition of unclear pathogenesis. The embryonic development of the hindbrain explains the origin of this primitive obstruction and its isolated character. In most cases, this atresia is semipermeable explaining the long time compensation state. The endoscopic approach is becoming the Gold standard treatment of a FVOO, however, if unavailable the open procedure remains effective and provides good results.

\section{Abbreviations \\ CSF: Cerebro spinal fluid; CT: Computed tomography; FVOO: Fourth ventricle outlets obstruction; MRI: Magnetic resonance imaging}

\section{Acknowledgements}

We sincerely thank Pr Guy Varlet for his assistance and advices.

Funding

No funding was available in support of this study.

Availability of data and materials

The authors declare that data supporting the findings of this study are available within this article.

Authors' contributions

HAN has performed surgery, drafted and revised the manuscript. LMK and SF assisted HAN for surgery. LMK revised the English language. All authors have accepted the final version for publication.

Ethics approval and consent to participate

The manuscript has ethics approval and consent to participate by the medical ethics committee of "CHU de Yopougon, Abidjan Côte d'Ivoire".

\section{Consent for publication}

A written form of consent for publication has been obtained from the patient involved. In the form the patient has agreed to publish her clinical information which are within the submission.

Competing interests

The authors declare that they have no competing interests. 
Received: 31 December 2016 Accepted: 26 June 2017

\section{Published online: 05 September 2017}

\section{References}

1. Ischi Y, Asaoka K, Kobayashi H, Motegi H, Sugiyama T, et al. Idiopathic fourth ventricle outlet obstruction successfully treated by endoscopic third ventriculostomy : a case report. Spriger Plus. 2015;4:1-7.

2. Inamura T, Morioka T, Nischio S, Ikezaki K, Nonaka H, et al. Diverticular enlargement of the foramina of Luschka and congenital hydrocephalus. Childs Nerv Syst. 2002;18:652-5.

3. Takami H, Shin M, Kuroiwa M, Isoo A, Takahashi K, Saito N. Hydrocephalus associated with cystic dilatation of the foramina of Magendie and Luschka. J Neurosurg Pediatr. 2010;5:415-8.

4. Rifkinson-Mann S, VP ES, Huang YP. Congenital fourth ventricular midline outlet obstruction. Report of two cases. J Neurosurg. 1987:67:595-9.

5. Volpe P, Campobasso G, De Robertis V, Rembouskos G. Disorders of prosencephalic development. Prenat Diagn. 2009;29:340-54.

6. Cotes C, Bonfarte E, Lazor J, Jadhau S, Caldas M, et al. Congenital basis of posterior fossa anomalies. Neuroradiol J. 2015;28:238-53.

7. Shekdar K. Posterior fossa malformations. Semin Ultrasound CT MR. 2011;32:228-41.

8. Maloney AFJ. Two cases of congenital atresia of the foramina of Magendie and luschka. J Neurol Neurosurg Psychiatry. 1954;17:134.

9. Longatti P, Fiorindi A, Martinuzzi A, Felleti A. Primary obstruction of the fourth ventricle outlets: neuroendoscopic approach and anatomic description. Neurosurgery. 2009:65:1078-85.

10. N'dri Oka D, Broalet MYE, Varlet G, Ba ZV. Un cas d'hydrocephalie chronique de l'adulte par l'occlusion congenitale de l'ouverture mediane du quatrieme ventricule traitée par foraminotomie et une duroplastie. AJNS. 2001;20:37-8.

\section{Submit your next manuscript to BioMed Central} and we will help you at every step:

- We accept pre-submission inquiries

- Our selector tool helps you to find the most relevant journal

- We provide round the clock customer support

- Convenient online submission

- Thorough peer review

- Inclusion in PubMed and all major indexing services

- Maximum visibility for your research

Submit your manuscript at www.biomedcentral.com/submit 